\title{
Editorial
}

\section{Origen de las revistas científicas, el caso de Odovtos}

La edición de revistas científicas en el ámbito universitario revela la efervescencia y la divulgación del conocimiento en las diferentes áreas del saber, por lo tanto la revista Odovtos, de la Facultad de Odontología de la UCR, ha sido en los últimos 18 años una generadora del saber del estado del arte en nuestra profesión.

Sabemos que antes de que el hombre inventara la escritura, existieron los libros vivientes (relatos orales por los hombres sabios) que pasaban a través de las generaciones con más creación y conocimiento; así fueron de boca en boca las tradiciones como La llíada y La Odisea en Grecia.

El ser humano, en su afán de comunicarse, no sólo de manera oral, optó por otra forma como fue pintar y hacer descripciones: primero en piedra de rocas en cavernas y luego en bronce a manera de cartas pictóricas, y dando testimonio de ello están las cavernas de Altamira, en España.

La primera escritura que se realizó fue el relato caldeo del diluvio universal, en una tablilla de arcilla del año 4000 a.C. La Biblioteca de Nínive contaba por ese tiempo con 30000 planchas de arcilla que habían sido escritas por los babilonios y asirios. Para una mayor y mejor manipulación y de peso, los seres humanos inventaron el papiro hacia el 2000 a.C., donde por medio de los jeroglíficos aún se pueden leer en los largos rollos en que fueron escritos. El papiro fue llevado a Roma, Grecia y a otros países para su venta y tenía un gran valor económico, y era manufacturado en Alejandría. Como el papiro resultaba ser muy costoso para los romanos, estos crearon las planchas de cera que podían ser reusables, ya que la cera se ablandaba y alisaba con gran facilidad para volver a escribir sobre ella.

Con la creación del pergamino, se abastecieron grandes bibliotecas con escritos griegos tales como las de Pérgamo, Alejandría y Efeso. Todos los escritos en ellas eran difícilmente reproducibles y, por lo tanto, su difusión era muy limitada.

El gran salto intelectual para el crecimiento y divulgación del saber por doquier, fue el invento de la imprenta en 1455 hecho por Gütenberg, quien realizó la impresión de La Biblia como su primer libro. La época del Renacimiento, fue acompañada de la impresión de miles de ejemplares de centenares de libros, lo que facilitó así la divulgación de nuevas ideas.

No fue sino hasta el año 1665 que aparecieron las revistas científicas tanto en Francia como en Inglaterra, y hace solamente 350 años que se escribieron los primeros importantes artículos científicos, que como en la actualidad tienen el objetivo de comunicar los resultados de la ciencia, preservar el conocimiento y certificar la calidad de las investigaciones. 
En Costa Rica las primeras publicaciones en las que se procuró difundir nuevos conocimientos, incluso científicos, fueron los periódicos, como el Mentor Costarricense, de 1842-1846, donde se incluían notas sobre avances tomados de publicaciones del exterior. Durante las dos últimas décadas del siglo XIX, comienza a realizarse investigación en el país, gracias al Instituto Físico-Geográfico de Costa Rica, y luego el Museo Nacional. Las primeras revistas de carácter divulgativo científico fueron Ios Anales del Instituto Físico Geográfico Nacional que se inició en 1888, publicado bajo la edición del Dr. Enrique Pittier. Este fue publicado hasta 1896 enfatizando la investigación en Botánica y Biología, y luego aparecieron nuevas revistas con un carácter divulgativo en Agronomía y ciencias afines como el Boletín de Fomento (1911-1924) y más tarde otras como la Revista de Agricultura (1929), la Revista del Instituto de Defensa del Café (1934). El Dr. Clorito Picado fue un insigne investigador, que logró grandes avances en medicina, divulgando mucho de su investigación entre 1915 y 1940.

Las primeras revistas editadas por la Universidad de Costa Rica se remontan al año 1945 y sus contenidos fueron principalmente tesis y discursos. En la actualidad la Universidad de Costa Rica publica una cantidad de 52 revistas científicas, las cuales, la mayoría han logrado estar oficializadas ante la Vicerrectoría de Investigación. Es a estas, a las que se les otorga mayor validez, ya que a su vez, también están indexadas e incluidas en el Catálogo del Latindex que abarca a lberoamérica y el Caribe. Además, existen otras tantas dentro del ámbito universitario, que son publicadas de manera independiente; algunas de ellas de gran trayectoria y prestigio internacional como lo es la Revista de Biología Tropical, que se viene editando desde 1953 de manera ininterrumpida y hasta la actualidad.

Además de las ediciones de revistas, los profesores universitarios produjeron folletos sobre diferentes temas de gran interés docente, entre los que se puede mencionar el de Lic. Rodrigo Facio con su Estudio sobre Economía Costarricense (1942).

Asimismo las conferencias que impartían algunos catedráticos a los grupos de estudiantes eran divulgadas en los años sesenta, tal fue el caso de las conferencias de los profesores Constantino Láscaris, Teodoro Olarte, Roberto Murillo y del sociólogo Marco Tulio Salazar, demás de otros notables profesores de la UCR.

Nuestra Facultad de Odontología, al igual que otras unidades académicas, inició a divulgar sus conocimientos y vivencias al inicio de los años setenta mediante un boletín informativo, que posteriormente se llamó Repertorio Odontológico. Este era elaborado de manera artesanal y repartido a profesores, alumnos y colegas por el Dr. Ramón García. Este fue todo un forjador de nuestra profesión, su labor docente se inició en 1943 o sea, casi desde la fundación de nuestra Facultad. Posterormente, en los años ochenta y parte de los noventa, nació una publicación formal tipo revista que continuó con el nombre de Boletín de la Facultad de Odontología, cuyo director fue el Dr. Alberto Monturiol V. La pretensión era que saliera de manera semestral, y su edición aunque tuvo éxito no logró la periodicidad deseada. Las ediciones, de 500 ejemplares, fueron impresas por la Oficina de Publicaciones de la UCR.

La Revista Odovtos se creó paralelamente junto al Programa Macro de Investigación en el año de 1998, siguiendo diferentes líneas de investigación previamente escogidas por los departamentos de la Facultad, para que abarcaran diversas disciplinas y especialidades en Odontología. En su inicio, los artículos fueron principalmente temas emergidos de los seminarios de graduación, que pertenecían 
al Programa Macro de Investigación y se generaron artículos interesantes sobre dichos análisis. Posteriormente, una gran cantidad de diferentes temas emergió por el interés de los profesores por publicar, no solo artículos de investigación, sino también de interesantes casos clínicos y revisiones bibliográficas con tópicos de punta del saber odontológico. De esta manera, la Revista Odovtos fue posicionándose, hasta lograr ser satisfactoriamente bien evaluada por Latindex e ingresar al Catálogo del Latindex. A su vez, fue oficializada ante la Vicerrectoría de Investigación de la UCR.

Con los años, muchos profesores de la Facultad en su esfuerzo por publicar, lograron ascender en Régimen Académico, aportándoles más prestigio a la revista Odovtos así como a la Facultad de Odontología.

La distribución de la Revista Odovtos, en el inicio, fue de 2000 ejemplares, y se distribuía de manera gratuita en diversas actividades académicas de la Facultad y mediante el Colegio de Cirujanos Dentistas, en los diferentes Congresos Nacionales y Regionales. Asimismo, se logró un activo intercambio con diferentes revistas odontológicas de Latinoamérica.

En el transcurso de estos dieciocho años, la revista Odovtos, que en sus primeros 15 años se editó de manera anual con un promedio de 16 artículos en cada volumen y auspiciada económicamente por empresas farmaceúticas, depósitos dentales y algunas clínicas dentales, en la actualidad, es una revista que se presenta en dos formatos, no solo impresa por el SIEDIN sino también de forma digital, bajo el sistema Open System.

En los tres últimos años, la revista Odovtos, ha dado un valioso salto cualitativo al haber ampliado de manera notoria la base de las indizaciones y ha llegado a 19 bases, entre las que se destacan ESCl, Web of Sciences, ROAD, MIAR y PROQUEST, además de obtener la máxima calificación en la evaluación de Latindex. Se ha logrado editar con una periodicidad cuatrimestral, por lo tanto, en los dos años últimos años han sido 9 las revistas que han visto la luz. Muy pronto la idea es que todas sus publicaciones aparezcan, tanto en español como en el idioma Inglés.

La revista, se vislumbra con orgullo que continuará creciendo en prestigio y difusión, y logrará mantener un alto nivel de visibilidad e impacto.

\section{Dra. Olga Marta Murillo Bolaños. MSc ${ }^{1}$}

1. Profesora Universidad de Costa Rica, Costa Rica. Ex-Directora Revista ODOVTOS-International Journal of Dental Sciences. Miembro Comité Editorial Revista ODOVTOS-International Journal of Dental Sciences.

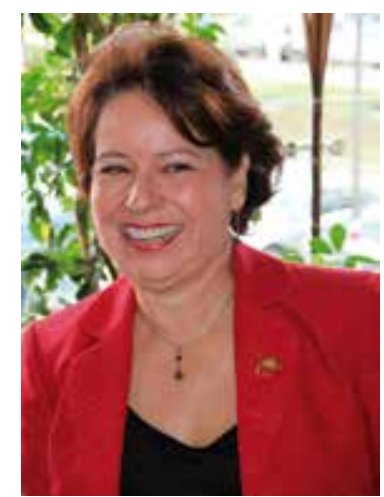

Attribution (BY-NC) - (BY) You must give appropriate credit, provide a link to the license, and indicate if changes were made. You may do so in any reasonable manner, but not in any way that suggest the licensor endorses you or your use. (NC) You may not use the material for commercial purposes. 